\title{
Proximate Analysis and Calorific Value Prediction using Linear Correlation Model for Torrefied Palm Oil Wastes
}

\author{
Siti Raishan Mohd Rashid, ${ }^{1, *}$, Suriyati Saleh ${ }^{1}$, and Noor Asma Fazli Abdul Samad ${ }^{1}$ \\ ${ }^{1}$ Faculty of Chemical \& Natural Resources Engineering, University Malaysia Pahang, Lebuhraya Tun \\ Razak, 26300 Gambang, Pahang, Malaysia
}

\begin{abstract}
Torrefaction is one of the pretreatment processes to upgrade the chemical and physical properties of biomass for power production. In this study, four types of palm oil wastes were selected. The wastes, which consisted of oil palm frond (OPF), palm kernel shell (PKS), palm mesocarp fibre (PMF), and empty fruit bunch (EFB), were subjected to torrefaction process at different temperatures of $240^{\circ} \mathrm{C}, 270^{\circ} \mathrm{C}, 300^{\circ} \mathrm{C}$, and $330^{\circ} \mathrm{C}$ for 30 min residence time. Based on the analysis of torrefied palm oil wastes, it was observed that there is a linear relationship between the properties of torrefied palm oil wastes and torrefaction temperature. Based on this, linear correlation model as a function of mass loss was developed to predict the energy yield (EY), calorific value (HHV), and proximate analysis. A reliable correlation model $\left(\mathrm{R}^{2}>0.90\right)$ for predicting calorific value (HHV), fixed carbon (FC), and volatile matter (VM) was obtained, indicating the developed linear model is indeed reliable. Meanwhile, an acceptable coefficient of determination $\left(\mathrm{R}^{2} \approx 0.75\right)$ was obtained when the linear model is used to estimate the energy yield (EY) and ash content (ASH). These developed linear correlation models are cost effective and can be used as a tool to predict the properties of palm oil wastes and to assess the suitability of biomass in torrefaction process.
\end{abstract}

\section{Introduction}

In Malaysia, palm oil industry is a major contributor in economic growth. Around 22.31 billion USD was generated from the palm oil industry in 2014, and it has been identified as the fourth largest source of national income [1]. Usually, the main products from palm oil industry are Crude Palm Oil (CPO), Palm Kernel Oil (PKO), and Palm Kernel Cake (PKC); these products are the common ingredients for a wide variety of food, feed, and non-food products [2]. Therefore, the demands for these products are continuous and expected to increase due to the population growth. In order to fulfil this demand, significant efforts have been made in terms of plantation expansion, thus increasing the palm oil cultivation. As a consequence, substantial amount of palm oil wastes such as empty fruit bunches (EFB), palm kernel shell (PKS), palm mesocarp fiber (PMF), and oil palm frond (OPF) are generated after

\footnotetext{
* Corresponding author: raishanrashid@gmail.com
} 
oil palm harvesting and palm oil processing. Current practices are to utilise these palm oil wastes for pelletisation and as a feed for boiler to generate electricity, while some of the wastes are just left to rot in the plantation for mulching and nutrient-recycling purposes [1]. Alternatively, these wastes can be transformed into value-added products or biofuel for cofiring processes at palm oil mills [3]. However, the main problem is that the energy produced from co-firing processes that use these palm oil wastes is relatively low and infeasible. This is due to the unfavourable characteristics of palm oil wastes such as high moisture content, low calorific value, and hygroscopic nature. In order to overcome this limitation, the palm oil wastes need to undergo a pretreatment process in order to improve their properties.

One of the common methods to upgrade the properties of palm oil wastes is by using torrefaction. Torrefaction is a thermal treatment process in the temperature range of $200^{\circ} \mathrm{C}-$ $300^{\circ} \mathrm{C}$ for a residence time between 15 and 60 min under inert condition. A vast study of torrefaction process has been implemented for various types of biomass and the resulting product from torrefaction is proven to exhibit brittle behaviour, high energy content, hydrophobic nature, and reduced mechanical strength [3-6]. In spite of that, the correlation analysis of the quality of torrefied product is rather limited. This correlation analysis is indeed important as a tool to assess the suitability of biomass in torrefaction process. This is due to the fact that although the torrefaction process is able to increase some of the properties, the increment for certain biomass is deemed low and insignificant. Therefore, there is a need for a simple correlation analysis to help in the biomass selection for torrefaction purposes. Through this correlation, the properties such as HHV and proximate analysis can be predicted and thus, the appropriate biomass can be selected for torrefaction purpose. It will reduce the needs to perform a number of experiments involving biomass and save a lot of time and energy. In this work, the objective is to develop a correlation analysis for predicting the properties of torrefied palm oil wastes. The torrefaction experiment of palm oil wastes is performed at temperatures of $240^{\circ} \mathrm{C}, 270^{\circ} \mathrm{C}, 300^{\circ} \mathrm{C}$, and $330^{\circ} \mathrm{C}$ for $30 \mathrm{~min}$ residence time. The torrefied palm oil wastes are then measured in terms of mass yield, energy yield, high heating value (HHV), and proximate analysis. Subsequently, the correlation model is developed for predicting the energy yield, HHV, and proximate analysis using the mass loss. The validity of this model is then evaluated using the coefficient of determination $\left(\mathrm{R}^{2}\right)$.

\section{Materials and methods}

\subsection{Palm oil wastes preparation}

Four types of palm oil wastes used in this study were oil palm frond (OPF), palm kernel shell (PKS), empty fruit bunches (EFB), and palm mesocarp fiber (PMF). The palm oil wastes were obtained from Lepar Hilir Palm Oil Mills, Kuantan, Pahang. Before experimental implementation, all of the palm oil wastes were oven-dried at $105^{\circ} \mathrm{C}$ for 4 hours to remove unbound water and to avoid the degradation of palm oil wastes. Afterwards, the samples underwent grinding and sieving process where only particles in the range of $0.5-1.0 \mathrm{~mm}$ were collected. The prepared samples were placed in an airtight container until the experiments are carried out.

\subsection{Torrefaction experiment}

Torrefaction of palm oil wastes was performed using a vertical-stainless steel reactor with $39.7 \mathrm{~cm}$ long and $1.9 \mathrm{~cm}$ internal diameter. An amount of 2-3 g of biomass samples were approximately measured and placed in the reactor for torrefaction process. The reactor was flushed with nitrogen gas at a flow rate of $10 \mathrm{~mL} / \mathrm{min}$ for $5 \mathrm{~min}$ as a carrier gas to create an inert environment. Afterwards, the biomass was heated to the desired torrefaction 
temperature $\left(240^{\circ} \mathrm{C}, 270^{\circ} \mathrm{C}, 300^{\circ} \mathrm{C}\right.$, and $\left.330^{\circ} \mathrm{C}\right)$ for 30 min residence time by an electric furnace. Various temperatures for torrefaction were applied to study the effect of physical and chemical changes behaviour in biomass at low and high torrefaction temperature. After the torrefaction process, the furnace was switched off and the reactor was allowed to cool to ambient temperature. The torrefied samples were then weighed to measure the mass loss of torrefied biomass. The torrefied samples were stored in an airtight container to avoid moisture from being trapped in the sample. For each temperature, the experiments were repeated for three times to enhance data reliability.

\subsection{Property analysis of torrefied palm oil waste}

The mass yield and energy yield were calculated by using Eqs. (1) and (2):

$$
\begin{gathered}
\text { Mass Yield (\%) }=\frac{\text { Mass of torrefied biomass }}{\text { Mass of raw biomass }} \times 100 \% \\
\text { Energy Yield }(\%)=\text { Mass yield } \times \frac{\text { Higher heating value of torrefied biomass }}{\text { Higher heating value of raw biomass }}
\end{gathered}
$$

Proximate analysis was conducted according to the American Society for Testing and Material (ASTM) standards. The volatile matter and ash content were calculated using Eq (3) - Eq (6) by referring to ASTM E871 [7], ASTM E872-82 [8], and E1755-01 [9] respectively while the fixed carbon content was calculated using Eq (7). The calorific analysis in the form of High Heating Value (HHV) was conducted using a bomb calorimeter.

$$
\begin{gathered}
\text { Moisture content }(\%)=\frac{m_{\text {initial }}-m_{\text {final }}}{m_{\text {initial }}-m_{\text {crucible }}} \times 100 \%=B \\
\text { Mass Loss }(\%)=\frac{m_{\text {initial }}-m_{\text {final }}}{m_{\text {initial }}-m_{\text {crucible }}} \times 100 \%=A \\
\text { Ash content }(\%)=\frac{m_{\text {ash }}-m_{\text {final }}}{m_{\text {initial }}-m_{\text {crucible }}} \times 100 \% \\
\text { Volatile Matter }(\%)=A-B
\end{gathered}
$$

Fixed Carbon $=100 \%-$ Volatile matter - Ash content - Moisture content

\section{Results and discussions}

The summary of properties of raw and torrefied palm oil wastes in terms of mass yield (MY), energy yield (EY), high heating value (HHV), fixed carbon (FC), volatile matter (VM), and ash content (ASH) is shown in Table 1 . Some of the data such as PKS, EFB, and OPF are collected from our previous work $[3,6]$. As shown in Table 1 , the mass yield for all palm oil wastes decreases as the torrefaction temperature is increased. This is due to the decomposition of palm oil wastes, particularly moisture content and hemicellulose constituent, into volatile components. However, the HHV value for all palm oil wastes shows an increasing trend when the torrefaction temperature is increased. As shown in Eq. (2), the $\mathrm{HHV}$ value affects the value of the energy yield but since the mass yield is decreased dominantly, in the end, the energy yield also decreases. Meanwhile, the fixed carbon and ash content for palm oil wastes increase, but the volatile matter shows the opposite trend. Overall, it can be concluded that all of the properties for palm oil wastes either decrease or increase linearly as the temperature is increased, which is in accord with other published literature $[5,10]$. Therefore a linear correlation model $(y=m x+c)$ has been developed in this work 
due to its simplicity and based on the observed linear trends. Here, the mass loss is used as the variable $(x)$ needed to predict the other properties $(y)$ of torrefied palm oil wastes. The mass loss is determined by subtracting mass yield (MY) from $100 \%$.

Table 1. Properties for raw and torrefied PMF, OPF, PKS, and EFB

\begin{tabular}{lcccccccc}
\hline Biomass & Condition & $\begin{array}{c}\text { MY } \\
\mathbf{( \% )}\end{array}$ & $\begin{array}{c}\text { EY } \\
\mathbf{( \% )}\end{array}$ & $\begin{array}{c}\text { HHV } \\
\mathbf{( M J} / \mathbf{k g})\end{array}$ & $\begin{array}{c}\mathbf{F C} \\
\mathbf{( \% )}\end{array}$ & $\begin{array}{c}\text { VM } \\
\mathbf{( \% )}\end{array}$ & $\begin{array}{c}\text { ASH } \\
\mathbf{( \% )}\end{array}$ & Ref. \\
\hline PMF & Raw & 100.00 & 100.00 & 16.94 & 18.42 & 75.23 & 6.35 & This work \\
& 240 & 84.21 & 94.54 & 18.05 & 27.84 & 66.07 & 6.08 & \\
& 270 & 75.61 & 90.87 & 19.17 & 28.73 & 64.60 & 6.67 & \\
& 300 & 68.01 & 92.46 & 21.49 & 33.33 & 59.58 & 7.10 & \\
PKS & 330 & 50.83 & 90.54 & 22.91 & 35.41 & 56.43 & 8.16 & \\
& Raw & 100.00 & 100.00 & 16.15 & 13.69 & 79.46 & 6.85 & {$[3]$} \\
& 240 & 84.43 & 102.26 & 19.68 & 26.45 & 66.27 & 7.28 & \\
& 270 & 77.64 & 104.70 & 21.91 & 26.17 & 65.70 & 8.13 & \\
EFB & 300 & 68.26 & 99.29 & 23.64 & 29.34 & 58.55 & 12.11 & \\
& 330 & 54.79 & 85.84 & 25.46 & 36.61 & 49.68 & 13.71 & \\
& Raw & 100.00 & 100.00 & 15.49 & 18.24 & 77.18 & 4.58 & {$[3]$} \\
& 240 & 82.84 & 83.36 & 15.59 & 30.79 & 62.51 & 6.70 & \\
OPF & 270 & 74.63 & 86.69 & 17.99 & 37.83 & 54.50 & 7.67 & \\
& 300 & 59.83 & 83.37 & 19.60 & 43.86 & 48.44 & 7.70 & \\
& 330 & 44.74 & 77.02 & 22.07 & 51.49 & 36.63 & 11.88 & \\
& Raw & 100.00 & 100.00 & 17.74 & 14.29 & 82.30 & 3.41 & {$[6]$} \\
& 240 & 87.76 & 98.00 & 19.82 & 31.93 & 64.86 & 3.20 & \\
& 270 & 77.52 & 94.34 & 21.60 & 39.23 & 56.15 & 4.62 & \\
& 300 & 56.98 & 78.27 & 23.79 & 49.70 & 45.54 & 4.76 & \\
\hline
\end{tabular}

Sum of squared residuals (SSR) is calculated in order to measure the discrepancy between the experimental data and estimation model as shown in Eq (8). The $y_{\exp }$ value is obtained from experimental data and $y_{\text {pred }}$ is obtained from the linear correlation model. A small SSR value indicates a tight fit of the model to the data while large value of SSR indicates the unreliability of the estimation model. Number of samples used to predict the energy properties for torrefaction process are $20,(N=20)$. In addition the $95 \%$ confidence interval is also determined for coefficients of $m$ and $c$ in the linear model.

$$
S S R=\sum_{i=1}^{20}\left(y_{\text {exp }}-y_{\text {pred }}\right)^{2}
$$

The linear correlation models as functions of mass loss for predicting the calorific value (HHV), energy yield (EY), fixed carbon (FC), volatile matter (VM), and ash content (ASH) for palm oil wastes are shown in Figs. 1(a)-(e). As shown in Figs. 1 (a)-(e), the linear correlation model for predicting HHV, FC, and VM shows $\mathrm{R}^{2}=0.92, \mathrm{R}^{2}=0.91$, and $\mathrm{R}^{2}=$ 0.93 respectively, indicating that a reliable correlation has been achieved. The experimental values for $\mathrm{HHV}, \mathrm{FC}$, and $\mathrm{VM}$ at different torrefaction temperatures $\left(240^{\circ} \mathrm{C}, 270^{\circ} \mathrm{C}, 300^{\circ} \mathrm{C}\right.$, and $330^{\circ} \mathrm{C}$ ) are very close to the linear line of correlation model which confirms that the linear model as a function of mass loss is a good indicator to represent the torrefaction process. Meanwhile, only $\mathrm{R}^{2}=0.74$ and $\mathrm{R}^{2}=0.77$ coefficients of determination have been obtained from linear correlation model for energy yield and ash content. Although low coefficients of determination are obtained, the linear model can be used to predict the energy yield and ash content, however, further comparison with other sources is necessary to improve the reliability of the predicted data. Furthermore, the upper bound and lower bound obtained from $95 \%$ confidence interval are also included in Figs. 1(a)-(e) where most of the properties data are lies within the bounds except energy yields and ash content which explains 
the low coefficients of determination is obtained for both properties. Overall, it can be concluded that all of the linear models can be used to predict the necessary properties data within the context of palm oil wastes.
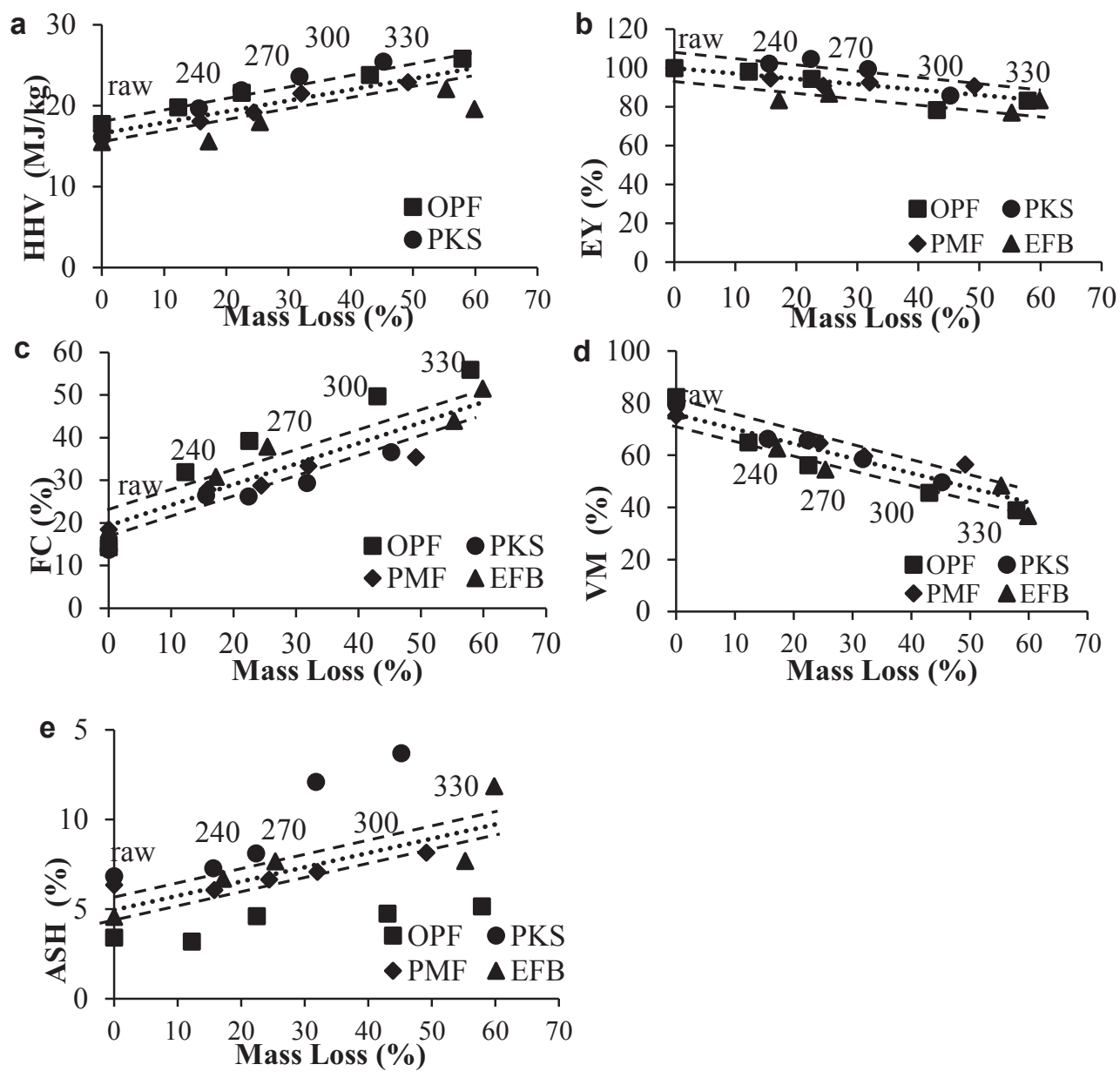

Fig. 1. Linear correlation model for (a) Calorific value (HHV); (b) Energy yield (EY); (c) Fixed carbon (FC); (d) Volatile matter (VM); (e) Ash content (ASH) as a function of mass loss.

The summary of simple linear correlation model with confidence interval for four types of biomass in terms of calorific value (HHV), energy yield (EY), fixed carbon (FC), volatile matter (VM), and ash content (ASH) as a function of mass loss is shown in Table 2. The SSR calculated for all properties are quite low (less than 5) indicating the predicted value using the model is very close to the experimental data for all data and thus the linear model is able to predict the desired properties. This model can be subsequently used for a preliminary assessment to determine the practicality of biomass to undergo torrefaction process. In this case, the values of calorific value (HHV), energy yield (EY), fixed carbon (FC), volatile matter (VM), and ash content (ASH) can be predicted by using the mass loss data only, without the needs to perform extensive experimental work and sample analysis. This is essential for example in gasification application where the simulation can be done using the predicted properties such as proximate analysis and HHV of torrefied biomass in order to evaluate the capability of torrefied biomass for producing synthesis gas and gasification 
efficiency [11]. This correlation model also helps in reducing the number of experiments to be implemented and thus, saves energy and reduces cost.

Table 2. Linear correlation model as a function of mass loss (ML) for palm oil wastes.

\begin{tabular}{llcc}
\hline Properties & Linear Correlation Model & $\mathbf{R}^{2}$ & (SSR) \\
\hline HHV $(\mathrm{MJ} / \mathrm{kg})$ & $\mathrm{HHV}=(0.135 \pm 0.00675) \times(\mathrm{ML})+(16.564 \pm 0.8282)$ & $\mathrm{R}^{2}=0.92$ & 0.89 \\
$\mathrm{EY}(\%)$ & $\mathrm{EY}=(-0.2767 \pm 0.1384) \times(\mathrm{ML})+(99.786 \pm 4.989)$ & $\mathrm{R}^{2}=0.74$ & 3.41 \\
$\mathrm{FC}(\%)$ & $\mathrm{FC}=(0.4826 \pm 0.02413) \times(\mathrm{ML})+(19.301 \pm 0.9651)$ & $\mathrm{R}^{2}=0.91$ & 2.72 \\
$\mathrm{VM}(\%)$ & $\mathrm{VM}=(-0.5618 \pm 0.02809) \times(\mathrm{ML})+(75.754 \pm 3.7877)$ & $\mathrm{R}^{2}=0.93$ & 0.74 \\
ASH (\%) & $\mathrm{ASH}=(0.0792 \pm 0.00396) \times(\mathrm{ML})+(4.9451 \pm 0.24726)$ & $\mathrm{R}^{2}=0.77$ & 4.09 \\
\hline
\end{tabular}

\section{Conclusions}

In this study, a linear correlation model has been developed for predicting the calorific value (HHV), energy yield (EY), fixed carbon (FC), volatile matter (VM), and ash content (ASH) specifically for torrefied palm oil wastes. High coefficients of determination $\left(\mathrm{R}^{2}>0.90\right)$ for linear correlation models for predicting HHV, FC, and VM have been obtained, which are applicable for palm oil wastes. This proves that the reliable model has been obtained and the mass loss is a suitable variable to predict the HHV, FC, and VM. However, moderate coefficients of determination $\left(\mathrm{R}^{2}<0.90\right)$ are obtained for linear correlation model for predicting the EY and ash content, thus, cautionary use of the correlation model is necessary. Overall, the linear correlation model developed in this study is a useful model to be used as an assessment tool for suitability of palm oil wastes for torrefaction process.

\section{Acknowledgements}

This work was financially supported by Doctoral Research Scheme (DRS) under Universiti Malaysia Pahang.

\section{References}

1. M.F. Awalludin, O. Sulaiman, R. Hashim and W.N.A.W. Nadhari, Renew. Sustainable Energy Rev. 50, 1469-1484 (2015)

2. D. Zwart, J Oil Palm Environ 4, 41-46 (2013)

3. N.H.H.M. Harun, F.R.A.A. Wahid, S. Saleh and N.A.F.A. Samad, Chem. Eng. Trans. 56, 1195-1200 (2017)

4. W-H Chen, J. Peng and X.T. Bi, Renew. Sustainable Energy Rev. 44, 847-866 (2015)

5. K.M. Lu, W.J. Lee, W-H Chen, S.H. Liu and T.C. Lin, Bioresour. Technol. 123, 98105 (2012)

6. F.R.A.A. Wahid, N.H.H.M. Harun, S.R.M. Rashid, N.A.F.A. Samad and S. Saleh, Chem. Eng. Trans. 56, 199-204 (2017)

7. ASTM E871-82, www.astm.org (2013)

8. ASTM E872-82, www.astm.org (2013)

9. ASTM E1755-01, www.astm.org (2015)

10. G. Almeida, J.O. Brito and P. Perre, Bioresour. Technol. 101(24), 9778-9784 (2010)

11. M.B. Muslim, S. Saleh, N.A.F.A. Samad, Chem. Eng. Trans. 56, 1495-1500 (2017) 